REGARDS

SUR L'ECONOMIE ALLEMAND

BULLETIN ECONOMIQUE DU CIRAC
Regards sur l'économie allemande

Bulletin économique du CIRAC

$73 \mid 2005$

Varia

\title{
Loisirs : les Allemands adorent les kermesses
}

Isabelle Bourgeois

\section{OpenEdition}

Journals

Édition électronique

URL : http://journals.openedition.org/rea/228

DOI : $10.4000 /$ rea. 228

ISBN : 978-2-8218-0842-3

ISSN : 1965-0787

Éditeur

CIRAC

Édition imprimée

Date de publication : 1 octobre 2005

Pagination : 38

ISSN : 1156-8992

Référence électronique

Isabelle Bourgeois, "Loisirs : les Allemands adorent les kermesses », Regards sur l'économie allemande [En ligne], 73 | octobre 2005, document 3, mis en ligne le 19 juin 2008, consulté le 15 septembre 2020. URL : http://journals.openedition.org/rea/228

Ce document a été généré automatiquement le 15 septembre 2020.

(C) CIRAC 


\title{
Loisirs : les Allemands adorent les kermesses
}

\author{
Isabelle Bourgeois
}

Dans leurs pratiques culturelles et de loisirs, les Allemands ressemblent beaucoup aux Français. Ils donnent ainsi priorité aux divertissements populaires, préférant de loin fréquenter les kermesses, les cinémas ou les musées. Les concerts de musique classique, les ballets ou l'opéra restent le privilège des milieux cultivés (bac+) et des revenus supérieurs. Seuls les musées attirent toutes les catégories CSP ; c'est là le fruit d'une récente politique visant à en démocratiser l'accès grâce à la multiplication d'expositions thématiques, d'événements multi-médias ou d'ouvertures exceptionnelles («longue nuit des musées»). A relever l'engouement des Allemands pour les centres de loisirs aquatiques, qui s'explique à la fois par une large diffusion des activités sportives dès la scolarité et l'existence d'infrastructures en nombre.

Les pratiques culturelles et de loisirs des Allemands

\begin{tabular}{|l|l|l|}
\hline \multicolumn{3}{|c|}{$\%$ des Allemands disant fréquenter de temps en temps ou souvent... } \\
\hline & $\begin{array}{l}\text { Manifestation sportive : } \\
56 \%\end{array}$ & Concert rock/variétés : $37 \%$ \\
\hline Kermesse $: 78 \%$ & Théâtre $: 55 \%$ & Café-concert/cabaret : $33 \%$ \\
\hline Musée : $70 \%$ & Bibliothèque $: 47 \%$ & $\begin{array}{l}\text { Concert de musique classique : } \\
29 \%\end{array}$ \\
\hline Cinéma : $68 \%$ & Comédie musicale : $41 \%$ & Centre culturel de quartier $: 24 \%$ \\
\hline $\begin{array}{l}\text { Centres de loisirs aquatiques : } \\
60 \%\end{array}$ & Concert open air : $40 \%$ & Opéra $: 23 \%$ \\
\hline
\end{tabular}


Parcs de loisirs : $58 \%$

Source : B.A.T. Freizeitforschungsinstitut/iwd 30/05. Enquête menée au printemps 2005 auprès de 2000 personnes de plus de 15 ans; réponses multiples possibles.

INDEX

Mots-clés : culture, loisir 